\title{
ANALISE VAN DIE OPBOU, ARGUMENTASIEGANG EN PRAGMATIEK VAN DIE GALATEBRIEF: 'N EERSTE ORIËNTERING
}

A B du Toit

ABSTRACT

ANALYSIS OF THE STRUCTURE, ARGUMENT AND PRAGMATICS OF GALATIANS: AN INITIAL ORIENTATION

Initially three methodological pitfalls regarding the analysis of the overall structure of Galatians are discussed: that of historical reconstruction of its polemical situation, of the rhetorical model and of the bipartite Pauline division between theological exposition and paraenesis. Then the macrostructural relations, the argument and the pragmatics of Galatians are analysed. Two main sections are identified, the first (Galatians 1:11-4:11) consisting of a double argument for the legitimacy of Paul's gospel, the second $(4: 12$ $6: 10)$ being an appeal concentrating on Christian freedom.

\section{Inleidend}

Die Pauliniese subgroep van die Nuwe-Testamentiese Werkgemeenskap van Suid-Afrika is reeds geruime tyd besig met ' $n$ navorsingsprojek oor die Galatebrief as oorredende teks. In hierdie verband het die groep, en in die besonder die projek-komitee, 'n diskoersanalise van die Galatebrief opgestel. Skrywer was deel van hierdie komitee en het in samewerking met Professor G M M Pelser gekonsentreer op die oorkoepelende opbou en gedagtegang van Galasiërs. Nie net laasgenoemde nie, maar al die voorgenoemdes word besonderlik bedank vir hulle insette waarop in hierdie stuk voortgebou kan word. Hierdie artikel is nietemin in wese die resultaat van eie navorsing en weerspieël nie noodwendig die standpunte van die subgroep nie. Om hierdie rede kan dit dien as gespreksbydrae tot die onderhawige onderwerp.

\section{Enkele metodologiese oorwegings}

In analises van die opbou van Galasiërs kan veral drie metodologiese gevaarpunte geïdentifiseer word.

2.1 Die gevaar van die verstaan van die opbou van Galasiërs vanuit historiese rekonstruksies aangaande sy polemiese situasie

Die verstaan van die Galatebrief ly onder ' $n$ lang tradisie van historiese konstruksies veral ten opsigte van die teenstanders in Galasië. Fletcher beweer nie sonder rede nie dat die Galate-eksegese van die laaste eeu onder die ban gestaan het van religionsgeschichtliche vraagstellings." Ondersoekers het hulle gehaas om Galasiërs 5-6 as 
paraneties met die oog op konkrete gevare te karakteriseer en dan voortgegaan met 'n ondersoek na Paulus se opponente. "For the most part it would be fair to say that a hasty identification of this section as paranetic seems to release scholars from the responsibility for thorough investigation of its broader function and allows them to seek immediately for historical clues in atomistic exegesis of its parts". ${ }^{2)}$ Afgesien van die ernstige probleme van "mirror-reading" wanneer 'n mens vanuit die Galasiërteks ' $n$ profieltekening van die Galasiese opponente wil maak, ${ }^{3)}$ kan nie ontken word dat hierdie diachrone konstruksies 'n bepaalde dwangbuiseffek op die verstaan van die teks gehad het nie. Die gepreokkupeerdheid met bepaalde gepostuleerde opponente het meegebring dat ons brief primêr gelees is as 'n soort strydgeskrif teen dwaalleer. Tipies hiervan is die feit dat die narratiewe gedeelte in Galasiërs 1-2 met eentonige reëlmaat gekarakteriseer is as ' $n$ verdediging van Paulus se apostelskap. ${ }^{4 l}$ Op hierdie wyse word 'n deehwaarheid verhef tot die volle waarheid en daarmee verwring tot 'n onwaarheid. 'n Tipiese voorbeeld van bogenoemde is die 1982-proefskrif van Brinsmead onder die sprekende titel: "Galatians - a dialogical response to opponents", ${ }^{5)}$ waarin die skrywer die ernstige gevaar van "spieëllees" verontagsaam en vanuit 'n ekstrapolasie van die opponente beweer: "the Galatians are in a sense the opponents... the whole letter will dispute the Galatians' acceptance of the intruder's false gospel". ${ }^{6}$ Die eksistensiële worsteling van die apostel om die herwinning van die Galasiers se lojaliteit teenoor die evangelie (vgl sy "barensnood" in 4:19) vergly op hierdie wyse in 'n teologiese dispuut oor botsende standpunte. Aune se kriptiese kommentaar op Brinsmead se wyse van tekshantering was dan ook dat dit "deur geloof alleen geregverdig kan word"."

2.2 Die gevaar van die afdruk van 'n andersoortige model op Galasiers, in besonder die retoriese model.

Een van die sterkste moderne tendense is om Galasiërs te wil inpas in die skema van die een of ander retoriese model. Sedert H D Betz se opspraakwekkende arbeid op hierdie gebied, ${ }^{8}$ ' het die penne oor die retoriese aspekte van Galasiërs nog nie weer tot rus gekom nie. ${ }^{9 \prime}$ ' $n$ Werklik gesaghebbende beoordeling vanuit die primêre bronne van die leemtes en verdienstes van die retoriese benadering tot die Nuwe-Testamentiese dokumente het ongelukkig nog nie verskyn nie. Dit is nietemin opmerklik dat Betz in die lig van ernstige probleme wat hy ondervind om Galate in die model van 'n apologetiese brief gebaseer op die retoriese model van die genus iudiciale ingepas te kry soos byvoorbeeld die feit dat hierdie soort skrywe nie paranetiese stof bevat het nie - verplig word om uiteindelik drie retoriese genres in Galasiërs te postuleer: Dis nie net 'n apologetiese brief nie, maar ook ' $n$ filosofiese traktaat en. les bes, word dit ook nog 'n "magiese brief". ${ }^{(0)}$ In 
sy erns om Galasiërs in retoriese skemas in te pas, moet Betz meer as een kunsgreep toepas soos ook later aangetoon sal word. In watter verleentheid hierdie benadering hom laat beland, blyk simptomaties uit Galasiërs 3-4. Hy ondervind in hierdie gedeelte, wat hy as die probatio, en daarom as die swaartepunt van Paulus se betoog karakteriseer, soveel probleme om 'n oortuigende retoriese patroon te vind, dat hy moet verklaar: "An analysis of these chapters in terms of rhetoric is extremely difficult . . . one might say Paul has been very successful as a skilled rhetorician should be - in disguising his argumentative strategy" (sic!)." Dit is verder ook nog opvallend hoe hy hom by 'n verleentheid van hierdie aard telkens op 'n opmerking van Quintilianus moet beroep. Smit ${ }^{12)}$ gaan selfs so ver om te beweer dat vanweë Quintilianus se ensiklopediese karakter en Betz se gebruikmaking van hom, dit moontlik sou wees om vir feitlik enigiets by Paulus ' $n$ parallel by Quintilianus te kry. Hierby kom nog 'n verdere verswarende oorweging: Daar bestaan onder die voorstanders van die retoriese benadering ernstige meningsverskil oor die vraag of Galasiërs wel tot die genus iudiciale (so Betz, Brinsmead, Hester, Harnisch) behoort of dalk eerder tot die genus deliberativum (Kennedy, Hall, Smit, Vougd). ${ }^{13)}$ Hoe meer sodanige modelle egter in die prentjie, kom en hoe meer die onderskeie voorstanders mekaar se benaderings kritiseer, hoe meer omstrede word die retoriese aanpak as sodanig.

Wat die kwessie ten opsigte van Paulus se bekendheid met en gebruikmaking van die retorika betref, is Aune waarskynlik naby aan die waarheid wanneer hy beweer: "though Paul was not trained in one consistent rhetorical tradition he was nevertheless a skilled eclectic speaker and writer able to combine many traditions and approaches in achieving the results and effects he desired". ${ }^{14)}$ Hierdie tegnieke en strategieë was sekerlik die gemeenskaplike besit van alle redelik ontwikkelde deelhebbers aan die Hellenistiese kultuur en ons kan aanvaar dat Paulus vryelik en eklekties van hierdie middele gebruik gemaak het waar en wanneer hy dit as funksioneel vir sy betoog beskou het. So weet ons byvoorbeeld sonder enige twyfel dat hy die Griekse briefprotokol gebruik het. Dit is trouens sekerlik die vorm waaraan hy hom die sterkste hou soos duidelik uit die studie van sy briewe aangetoon kan word. Tog hou hy hom ook hieraan geensins pedanties nie. Wanneer ons egter soos hierbo die woord "eklekties" gebruik, word dit begryplikerwys uiters riskant om bepaalde retoriese skemas in die Galasiërteks te probeer vind indien daar nie werklik duidelike indikasies in die teks self voorkom nie. Hierteenoor het ons wel duidelike indikasies dat Galasiërs in hooftrekke met die konvensies van 'n Hellenistiese brief rekening hou. Hiermee word nie ontken dat Paulus binne raamwerk van die brief wel eklekties van retoriese strategieë gebruik gemaak het nie. ${ }^{15}$ ) Om dit te sê, is egter nog iets heeltemal anders as om die opbou van Galasiërs volgens retoriese genres en indelingsbeginsels te bepaal. 
In my meer gedetailleerde uiteensetting sal verder met Betz in gesprek getree word. Op hierdie stadium wil ek nog net wys hoe die verklaring van die Galatebrief vanuit ' $n$ vooropgesette retoriese model in hele verskuiwing ten opsigte van die aard en pragmatiek van hierdie geskrif meebring. In sy samevatting van die argumentatiewe situasie van Galasiërs beskryf Betz hierdie brief as 'n selfapologie waarin, binne die forensiese kader, Paulus die aangeklaagde, die anti-Pauliniese agitasie die aanklaer en die Galasiese gemeentes die jurie is. ${ }^{16)}$ Alhoewel Betz die oorredingskarakter van Galasiërs erken, word ons brief op hierdie wyse 'n openbare verdediging van die korrektheid van Paulus se standpunte. Daarmee word die pastorale karakter van hierdie briet, waarin die apostel as diep bekommerde en hoogs ontstelde geestelike vader soms hartstogtelik pleit, soms dreig, soms verwyt en in elk geval alle moontlike strategieë in die werk stel om sy geloofskinders vir die kruisevangelie terug te wen, in gedrang gebring.

2.3 Die gevaar van die afdwing van 'n Pauliniese tweedelingsmodel op die Galatebrief.

Die vooropgesette idee dat die hoofbetoog van 'n Pauliniese brief vanselfsprekend uit 'n leerstellig-teologiese en 'n paranetiese deel behoort te bestaan, het tradisioneel 'n onuitgesproke maar tog duidelik waarneembare invloed op die indeling van die Galatebrief uitgeoefen. ${ }^{17}$ Dit het trouens selfs tot onlangs invloed uitgeoefen op die analise van 'n geskrif so ver verwyder van die Paulusbriewe soos Hebreërs. ${ }^{18}$ Hoe onverantwoord so ' $n$ aprioriese benadering inderdaad is, blyk alreeds uit die feit dat hierdie tweedeling glad nie so volop in die corpus Paulinum voorkom as wat gewoonweg aanvaar word nie. In die ander onomstrede Paulusbriewe kom hierdie tweedeling in werklikheid net in Romeine en 1 Tessalonisense voor. Ook die opvallende inhoudelike ooreenstemmings tussen Galasiërs en Romeine maak dit nog nie vanselfsprekend dat ons ook in eersgenoemde so ' $\mathrm{n}$ tweedeling moet vind of selfs noodwendig 'n nuwe paranetiese deel in Galasiërs 5:13vv nie. Basies moet egter gestel word dat 'n beslissing oor die vraag of Galasiërs uit ' $n$ leerstellig-teologiese en 'n paranetiese hoofdeel bestaan, en selfs of Galasiërs 5:13-16 'n belangrike nuwe hoofdeel uitmaak, aan die teks self gevel en beredeneer sal moet word en nie apriories na die teks toe aangedra behoort te word nie.

Samevattend moet gestel word dat al drie bogenoemde gevare basies uit een gemeenskaplike metodologiese dwaalweg voortspruit: die inbring van verstaans-apriorieë wat nie organies uit die teksaanbieding self voortkom nie. ${ }^{19)}$ Negatief gaan dit daarom dat die teks nie ingedwing mag word in modelle en insigte wat belowend lyk, maar wat tog nie probleemloos op die teksinhoud pas nie; positief om die noodsaaklikheid dat elke poging aangewend moet word om die integriteit van die teksgegewens te eerbiedig. Die teksimmanente benadering het 
sy ernstige tekortkominge en is reeds daarom geen towerlampie van Aladdin nie, maar dit bly nietemin in hierdie konteks die "uitnemender weg".

\section{Die eenheid van Galasiërs}

Vir die bespreking van die komposisionele karakter van Galasiërs is dit wesenlik belangrik om eers te vra na hierdie geskrif se oorspronklike eenheid. Die oorspronklike eenheid van Galasiërs word vandag selde bevraagteken. Twee onlangse uitsonderings is $\mathrm{J} \mathrm{C} \mathrm{O} \mathrm{Neil}{ }^{201}$ en J Smit ${ }^{21}$ Laasgenoemde sê nie sonder rede nie van O'Neil se poging: "this work has rightly received little attention".22

Smit self ${ }^{23 t}$ is van mening dat Galasiërs 5:13-6:10 aan 'n latere redaksie toegeskryf moet word omdat in hierdie vermanende gedeelte alle verwysings na opponente ontbreek, onderlinge gemeenteverhoudings aan die orde is, ' $n$ ander begrippe-apparaat gebruik word, 'n ander gesigshoek voorkom (meer algemeen) en die toon veel meer ironies is. Smit se opmerkings kan inderdaad nie ligweg opsy geskuif word nie. Dit kan nie geignoreer word dat die opponente nie in hierdie gedeelte genoem word en dat hierdie gedeelte ook in ander opsigte van die res van Galasiërs verskil nie. Nietemin kan al hierdie verskille verklaar word uit die feit dat Paulus dit wat hy in die voorafgaande gedeeltes van Galasiërs gestel het, nou meer persoonlik op die binnegemeentelike verhoudings en trouens op die optrede van alle Christene toepas. Daarby gaan dit in hierdie toepassing nie meer om die stryd teen die dwaalleer nie, maar om die positiewe uitlewing van die Pauliniese evangelieverkondiging, wat volgens Paulus sonder meer die enigste ware evangelie is. Ook sal later aangetoon word dat hierdie gedeelte in werklikheid geen Fremdkörper is nie, maar organies voortspruit uit Paulus se voorafgaande betoog. Ons kan dus met vrymoedigheid aanneem dat Galasiërs as 'n eenheid deur Paulus geskrywe is en wel. afgesien van enkele tekskritiese onsekerhede, soos dit as teks voor ons lê.

\section{Die oorkoepelende opbou, argumentatiewe struktuur en pragmatiek van Galasiërs}

Om die oorspronklike eenheid van Galasiërs te aanvaar, beteken nog nie noodwendig om te aanvaar dat hierdie geskrif 'n hegte komposisionele eenheid is en 'n hegte tematiese, argumentatiewe en pragmatiese binding vertoon nie. Na geruime tyd van worsteling met hierdie moeilike teks, is skrywer egter daarvan oortuig dat Galasiërs sterk koherensie op tematiese, argumentatiewe sowel as pragmatiese vlak vertoon.

Met inagneming van die destydse briefprotokol kan die makrostrukturele verbande van Galasiers soos volg saamgevat word: 

A. $1: 1-5$
B. 1:6-10:

C. $1: 11-4: 11$

Aanloop tot hootbetoog bevattende in implisiete aanduiding van die aanleiding tot skrywe en van die saak waarom dit in die brief gaan. Negatief lui hierdie saak: Daar is geen ander evangelie nie. Positief kan dit geformuleer word: Daar is net een ware evangelie: die een wat Paulus verkondig.

Argumentatiewe fase:

C.1 Eerste argument: 1:11-2:21: Die outentisiteit van die Pauliniese kruisevangelie blyk eerstens daaruit dat hy hierdie evangelie en sy opdrag van God ontvang het en nie van mense nie.

C.2 Tweede argument: 3:1-4:11: Die outentisiteit van die Pauliniese kruisevangelie blyk tweedens daaruit dat dit slegs deur hierdie evangelie is dat gelowiges die Heilige Gees ontvang het en erfgename is van al God se heilseëninge. Dit is volledig onbegryplik dat hulle weer na die ou knegskap sal wil terugkeer.

D. $4: 12-6: 10$

Appèllerende fase: Voortvloeiend uit die voorafgaande argumentasie appelleer Paulus op die Galasiërs om vas te staan in hulle Christelike vryheid. Hierdie vryheid moet egter reg gebruik word deur mekaar in liefde te dien.

E. 6:11-18:

Briefafsluiting: Sterk konkluderende appèl. Die Galasiërs moenie toegee aan diegene wat op hulle fisiese staat ( $=$ hulle besnedenheid) wil roem nie. Wie die evangelie glo, roem soos Paulus in die kruis.

Soos hierbo aangedui, kan die oorkoepelende tema van Galasiërs geformuleer word: Daar is net een ware evangelie: Die kruisevangelie soos deur Paulus verkondig.

Die oorkoepelende oorredingsdoel of pragmatiek sou wees om die Galasiërs daartoe te bring dat hulle die dwaalbeskouings sal afsweer en weer tot hierdie ware evangelie sal terugkeer.

Kombineer ons tematiek en pragmatiek en formuleer ons dit vanuit die gesigshoek van die skrywer, sou ons dit soos volg kon stel:

Die Kruisevangelie soos ek dit aan julle verkondig het, is die enigste ware Evangelie. Ek pleit by julle: keer terug daarheen. 
Die doel van hierdie artikel is nie om bostaande ontwerp in detail tot op perikoopvlak te beredeneer en met die ter sake literatuur daaroor in diskussie te gaan nie. Volgens beplanning sal 'n volgende artikel die opbou van Galasiërs tot op mikrovlak aan die orde stel. Op hierdie stadium word slegs die oorkoepelende verdeling van Galasiërs en die breë gang van die betoog soos dit in die skema hierbo uiteengesit is, beredeneer.

Reeds die briefaanhef $(1: 1-5)$ met sy bekende en geykte driedeling is sterk funksioneel. Antisiperend op sy latere beredenering van die legitimiteit van sy evangelie "foreground" die skrywer die goddelike herkoms van sy bediening. Ook die intrinsieke genadekarakter van sy evangelie word nou reeds sterk uitgelig (v.4).

Die aanloop tot die hoofbetoog, met sy striemende, vooropgestelde $\theta \alpha u \mu \alpha \zeta \omega$ is in die skets hierbo afgebaken as bestaande uit Galasiers 1:6-10. Oor die begin van hierdie perikoop kan geen meningsverskil bestaan nie, omdat dit baie duidelik is dat die salutatio met vers 5 eindig. Daar bestaan egter sterk meningsverskil oor die vraag of vers 10 nog deel van hierdie perikoop uitmaak. Ook die Aland-teks en dié van die United Bible Societies verskil op hierdie punt. Eersgenoemde eindig die perikoop met vers 9 (alhoewel met 'n duidelike lakune tussen verse 10 en 11), terwyl laasgenoemde die skeiding eers tussen verse 10 en 11 maak. Die probleem word veroorsaak deur die dubbelslagtige karakter van vers 10. Dit vervul duidelik 'n oorgangsfunksie. Die belangrikste rede waarom besluit is om vers 10 as deel van die voorafgaande te hanteer, lê in die voorkoms -- in vers 11 - van die bekendmakingsformule ("disclosure formula") y

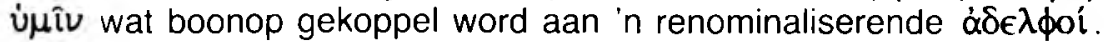
Albei hierdie verskynsels dui op ' $n$ nuwe inset in vers 11 . Uit die linguistiek weet ons dat renominalisasie 'n bekende verskynsel is by nuwe insette. Waar Paulus in die voorafgaande gedeelte (verse 6-10) vier keer na mekaar die tweede persoon-voornaamwoord gebruik het, renominaliseer hy nou in vers 11. Daarby dra die bekendmakingsformule op sigself reeds besondere gewig en Paulus reflekteer dit deur hierdie uiting in die semanties prominente eerste sinsgleuf van vers 11 te plaas. Dit is dan ook nie sonder rede dat in al agt ander gevalle wat die bekendmakingsformule by Paulus saam met die woord "broers" verskyn, dit 'n nuwe linguistiese eenheid inlui nie (Rom. 1:13 (sic!); $11: 25 ; 1$ Kor. $10: 1 ; 12: 1 ; 15: 1 ; 2$ Kor. $1: 8 ; 8: 1 ; 1$ Tes. $4: 13)$.

Soos blyk uit Galasiërs 1:6vv is Paulus duidelik hoogs ontsteld oor die (dreigende) afvalligheid van die Galasiese gemeentes na ' $n$ "ander evangelie" toe. Met sy verwysing na die "ander evangelie" wat in werklikheid geen evangelie is nie, maar 'n verdraaiing van die Christusevangelie (vers 7) en sy energiese reaksie teen die afvalligheid van die Galasiese Christene het Paulus by implikasie die tematiek en pragma- 
tiek van die Galatebrief soos hierbo geformuleer, aangedui. Hy werp nou alles in die stryd om die lojaliteit van hierdie gelowiges aan die kruisevangelie te herwin. Hy gaan dit negatief doen deur die menslike karakter en die armoede van die opponente se "evangelie" skerp uit te lig. Hy doen dit bo alles positief deur die outentisiteit (1:11-2:21), die rykdom (3:1-4:11) en die vryheid $(4: 12-6: 10)$ van die evangelie wat hy verkondig, daar te stel.

Die argument om die outentisiteit of legitimiteit van die evangelie wat Paulus verkondig, daar te stel (punt $\mathrm{C}$ op die raamwerk hierbo) verloop in twee fases waarvan die eerste $(C .1)$ 'n histories-verhalende karakter besit en die tweede (C.2) 'n histories-beredenerende karakter.

In die eerste fase (1:11-2:21) beklemtoon Paulus deur middel van verskeie narratiewe terugblikke op sy roeping en bediening dat sy evangelie nie van menslike oorsprong is nie en dat hierdie feit erken en gestaaf is in verskillende episodes tydens sy bediening.

In die tweede fase (3:1-4:11), waarin die armoede van die wettisisme met die rykdom van die "Pauliniese" evangelie gekontrasteer word, argumenteer die apostel met die Galasiërs dat hulle Geestesbesit voortgevloei het uit die verkondiging van die regverdiging deur die geloof, dit wil sê uit die prediking van hierdie selfde kruisevangelie, en nie uit wetswerke nie. Die Geestesbesit van die Galasiërs is dus die tweede "bewys" vir die legitimiteit van Paulus se evangelie. Die Gees word in hierdie gedeelte vyf keer pertinent genoem $(3: 2,3,5,14$ en $4: 6)$ en daarby figureer Hy prominent in die semanties so belangrike aanvangsgleuf van hierdie deel $(3: 2-4)$ en weer in die klimaktiese perikoop Galasiërs 4:1-7.

Dit is uiters moeilik om te beslis of die perikoop Galasiërs 4:8-11 nog by hierdie tweede argument hoort of by die volgende fase van die betoog. ${ }^{24)}$ Die rede hiervoor lê in hierdie perikoop se ambivalente karakter. Dit is in werklikheid 'n nexus tussen hierdie twee gedeeltes. Die dominerende motief van verslawing bind anafories (vgl. 4:1,3,7) sowel as katafories (vgl. 4:21-31; 5:1). Ten gunste van koppeling met Galasiërs 4:12vv spreek ook nog verder die noue skakeling tussen die verwysings na Paulus se arbeid onder hulle (4:11 en 4:12vv). Die rede waarom ek dit tog met die voorafgaande verbind, lê in die noue verband

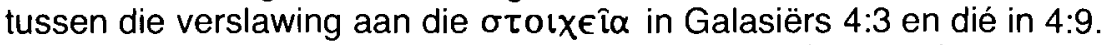
Daarbenewens sluit die motief van "vergeefsheid" in 3:4 in 'n mate ringvormig aan by diě in $4: 11$. Beslissing na die een of ander kant toe maak egter in hierdie geval nie 'n dramatiese verskil nie.

Die tweede hoofdeel van die betoog $(4: 12-6: 10)$ met sy sterk klem op die Christelike vryheid, besit 'n baie duidelike appellerende karakter. In werklikheid het reeds die voorafgaande argument 'n implisiete appèl bevat omdat die apostel hier 'n beroep gedoen het op sy lesers se redelikheid en die dwaasheid van 'n hernieude verslawing so sterk 
beklemtoon het. Hierdie nuwe deel (D) se appellerende karakter blyk egter reeds eksplisiet uit die imperatief aan sy begin (4:12), asook die direk-persoonlike, soms selfs pleitende aanspreke (byvoorbeeld 4:19$20,28,31 ; 5: 11,13)$. Waar die aanspreekvorm $\dot{\alpha} \delta \in \lambda \phi o i ́$ in die eerste drie hoofstukke net twee keer voorgekom het $(1: 11 ; 3: 15)$, word dit in hierdie gedeelte ses keer aangewend $(4: 12,28,31 ; 5: 11,13 ; 6: 1)$. Na die logiese "bewysvoerings" van die eerste hoofdeel, doen Paulus nou 'n gelaaide persoonlike oproep op sy geloofskinders om na die oorspronklike evangelie, die evangelie van vryheid, terug te keer en hulle nie opnuut te laat verslaaf nie. Die motief van die vryheid van die evangelie $(4: 22,23,26,30,31 ; 5: 1,13)$ word appellerend skerp afgeëts teen die slawerny van die wettiese benadering $(4: 22,23,24,25,30,31 ; 5: 1)$. Die geweldige emotiewe gewig van hierdie metaforiese kontraspaar bevat appellerende plofkrag.

'n Belangrike kwessie is die posisie van Galasiërs 5:13-6:10. In aansluiting by Dippenaar ${ }^{25}$ is hierdie gedeelte nie as ' $n$ nuwe hoofdeel van die Galatebrief hanteer nie. Die vraag is of hierdie standpunt korrek is. Moes ons nie hier na analogie van ander Paulusbriewe 'n nuwe paranetiese hoofdeel aangemerk het nie? Ons het reeds daarop gewys dat die teksinterne gegewens van Galasiërs self by hierdie beslissing die deurslag behoort te gee. Vergelyk ons Galasiërs 5:13vv met Romeine $12: 1 \mathrm{vv}$ en ook met 1 Tessalonisense $4: 1 \mathrm{vv}$, tree ' $n$ paar opvallende verskille na vore. In Romeine sowel as in 1 Tessalonisense word die paranese prominent ingelei met 'n oûv paraneticum sowel as 'n

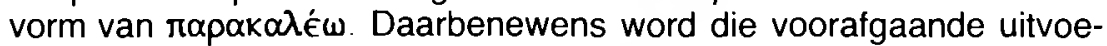
rings in albei gevalle plegtig met 'n doksologie of gebed afgesluit (Rom. $11: 33-36 ; 1$ Tes. $3: 11-13$ ). Dieselfde is ook trouens die geval met die brief aan die Efesiërs. Ook hier word die teologies-lerende gedeelte met ' $n$ doksologie afgesluit en begin die paranetiese gedeelte met 'n

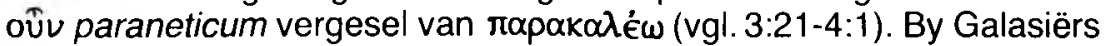
kry ons niks van hierdie aard nie. Daarbenewens sluit Galasiërs 5:13 met sy klem op die regte aanwending van die Christelike $\dot{\epsilon} \lambda \in v \theta \epsilon \rho i \alpha$ direk by die voorafgaande aan. Ook die sterk beklemtoning van die rol van die Heilige Gees in die regte beoefening van die Christelike vryheid $(5: 16,17,18,22,25 ; 6: 8 \mathrm{vgl} 6: 1)$ sluit integraal aan by die voorafgaande klem op die Heilige Gees $(3: 2,3,5,14 ; 4: 6,29 ; 5: 5)$. In die lig van bogenoemde kan ons wel praat van 'n wending na die paranetiese in 5:136:10, maar sou dit nie verantwoord wees om hier 'n nuwe, paranetiese hoofdeel te laat begin nie. Die paranetiese wending maak inteendeel nog integrale deel van die appellerende fase van die hoofbetoog uit. Ons kan hier ' $n$ analogie met die verhouding tussen Romeine 5 en 6 trek. Waar Paulus in Romeine 5 besondere klem op die genade geplaas het, reageer hy in Romeine 6 teen 'n libertinistiese waninterpretasie wat uit sy stelling mag ontstaan dat die toename van sonde die genade nog oorvloediger laat word (Rom. 5:20). In sy bekamping van 
hierdie waninterpretasie (wat trouens volgens Rom. 3:8 ook ' $n$ ernstige kritiek is wat teen hom ingebring is) beweeg Paulus gaandeweg oor van die indikatief na die imperatief ${ }^{26)}$ Daarom het veral die laaste deel van Romeine 6 ' $n$ sterk paranetiese inslag.

Dieselfde verskynsel kry ons in Galasiërs 5. Nadat Paulus die Christelike vryheid in die voorafgaande so sterk beklemtoon het, beskou hy dit nou in Galasiërs 5:13vv as noodsaaklik om teen 'n libertinistiese misbruik van daardie vryheid (en moontlike beswaddering deur die dwaalleraars?) wal te gooi en beweeg hy op analoë wyse van die indikatief na die imperatief. Die paranese staan onder die prominente gesigspunt van die beheersing deur die Gees. Dit sou dus net so min korrek wees om 'n makrostrukturele skeiding tussen Galasiërs 5:12 en 5:13 te maak as tussen Romeine 5 en 6.

Ook die eiehandig-geskrewe briefslot (6:13-18) staan nog steeds in diens van die oorkoepelende tematiek en pragmatiek van hierdie brief. Die "goeie vertoning in die vlees" word diametraal teenoor die kruisevangelie gestel (6:11-16). Die intiem-persoonlike wyse waarop die kruisevangelie aan Paulus se geestelike en fisieke menswees verbind word, bevat ' $n$ roerende implisiete appèl. Die spanningslyn van onversoenbares wat reeds in Galasiërs 1:1 begin het (oủk ó $\pi$ '

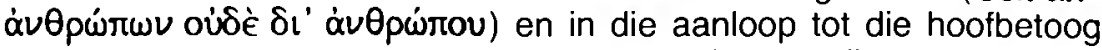
(1:6-9) sy beslag gekry het met die kontrastering van die ware evangelie teenoor die "ander evangelie", word deur al ses hoofstukke van

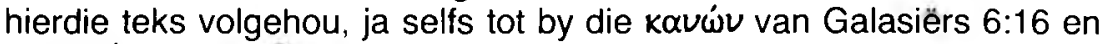

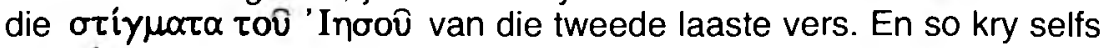
die $x$ ópls van die seëngroet $(6: 18)$ weer sy oorspronklike glans terug. Inderdaad: Geen ander brief van Paulus vertoon 'n hegter komposisionele eenheid as die Galatebrief nie.

\section{NOTAS}

1. D K Flelcher, The singular argument of Paul's letter to the Galatians (UMI 3592), Ann Arbor 1982, 6.

2. Fletcher, a.w., 5.

3. Vgl. die uitstekende artikel van J M G Barclay, "Mirror-reading a polemical letter. Galatians as a test case", JSNT vol 31 (1987), 73-93.

4. Grondige kritiek hierteen by B C Lategan, "Is Paul defending his apostleship in Galatians? The function of Galatians 1.11-12 and 2.19-20 in the development of Paul's argument". NTS vol 34 (1988), 411-430.

5. B H Brinsmead, Galatians - dialogical response to opponents (SBLDS 65), Chico 1982.

6. Brinsmead, a.w. 188.

7. D E Aune, Review, CBQ vol 46 (1984), 147.

8. H D Betz, "Geist, Freiheit und Gesetz", ZThK vol 71 (1974), 78-93; "The literary composition and function of Paul's letter to the Galatians", NTS vol 21 (1975), 353- 
379; Galatians. A commentary on Paul's letter to the churches in Galatia (Hermeneia), Philadelphia 1979.

9. Vgl bv G A Kennedy, New Testament interpretation through rhetorical criticism. Studies in religion, Chapel Hill \& London 1984; H Hübner, "Der Galaterbrief und das Verhältnis von antiker Rhetorik und Epistolographie", ThLZ vol 109 (1984), Sp 241-249; J D Hester, "The rhetorical structure of Galatians 1:11-2:14", JBL vol 103 (1984), 223-233; R G Hall, "The rhetorical outline for Galatians. A reconsideration", JBL vol 106 (1987), 277-287; J Smit, Opbou en gedachtegang van de brief aan de Galaten. Vier studies (doctorale proefschrift), Nijmegen 1987; "The letter of Paul to the Galatians; a deliberative speech", NTS vol 35 (1989), 1-26.

10. Betz, a w 1979, veral bl 379.

11. A.w.1979, 369.

12. A.w.1989, 6 .

13. Genus iudiciale: Betz, a.w. 1975; a.w. 1979; Brinsmead, a.w.; Hester, a.w.; W Harnisch, Einübung des neuen Seins. Paulinische Paränese am Beispiel des Galaterbriefes, ZThK vol 84 (1987), 279-296; genus deliberativum: Kennedy, a.w.; Hall, a.w.; Smit, a.w. 1989; F Vouga, Zur rhetorischen Gattung des Galaterbriefes, ZNW vol 79 (1988), 291-292.

14. D E Aune, Review, Religious Studies Review vol 7 (1981), 326.

15. Hierdie standpunt het ek beredeneer in my artikel "Persuasion in Romans 1:1-17", $B Z$ vol 13 (1989), 192-209.

16. Betz, a.w., 1975, 377 .

17. Talle kommentare beskou Galate 5:13-6:10 as 'n belangrike nuwe fase in die makrostruktuur.

18. Kyk my artikel "Die oorkoepelende opbou en gedagtegang van Hebreërs", in L Nortje (red), Die vriend in ons poorte ( $P J$ du Plessis feesbundel), (in die pers).

19. Hiermee word die hermeneutiese insig dat ons nooit sonder bepaalde verstaansapriorieë na die teks gaan, natuurlik nie ontken nie. Hierdie verstaansvoorveronderstellings mag egter nie teen die grein van die teks in daarop afgedwing word nie.

20. J C O'Neil, The recovery of Paul's letter to the Galatians, London 1972.

21. A.w., 1986, 93-123.

22. A.w., 1989, 8 voetnoot 4 .

23. A.w.,1986, 93-123; a $w 1989,25$. Hierdie is ook O'Neill, a $w, 65-71$ se standpunt.

24. So bv M C Dippenaar, "Paul's defense of the gospel against Peter in Antioch with emphasis on justification through faith alone (Galatians $2: 11-21$ )". Artikel verskyn eersdaags in Theologia Viatorum vol 18 (1990).

25. A.W.

26. Kyk A B du Toit, "Dikaiosyne in Röm 6", ZThK vol 76 (1979), 261-291. 